\title{
Experimental investigation and Taguchi optimization of turning process parameters for glass fiber reinforced plastics (GFRP)
}

\author{
S. Jasper ${ }^{1}$, B. Stalin ${ }^{2 *}$ and M. Ravichandran ${ }^{3}$ \\ PG Scholar, Department of Mechanical Engineering, Anna University, Regional Campus Madurai, Keelakuilkudi, \\ Madurai, Tamilnadu, India ${ }^{1}$ \\ Assistant Professor, Department of Mechanical Engineering, Anna University, Regional Campus Madurai, \\ Keelakuilkudi, Madurai, Tamilnadu, India ${ }^{2}$ \\ Associate Professor, Department of Mechanical Engineering, K.Ramakrishnan College of Engineering, \\ Tiruchirappalli, Tamilnadu, India ${ }^{3}$
}

(C2018 ACCENTS

\begin{abstract}
The recent research work has been carried out under the parameters of cutting speed, feed rate and depth of cut in which the material removal rate, machining time and the surface roughness on the glass fiber reinforced plastic (GFRP) composite material during the turning process was analyzed. The objective of this work, is to focus the machining characteristics of GFRP are inspected under the Taguchi Design method. And hence the experimental results are carried out as per the Taguchi experimental design and an L9 orthogonal array is observed through the design of experiment and it is used to study the influence of surface quality parameters. This method is to achieve the optimal control factor of the machining process parameters such as surface roughness, machining time and material removal rate. And finally to determine the optimal levels of the parameters the analysis of means (ANOM) will be performed. In addition to identify the level of importance of the machining parameters the analysis of variance (ANOVA) has to be employed. These analysis results revealed that the major contribution of the process parameter such as surface roughness was the most influential factor on the feed rate, and for machining time, speed is the major influencing factor and for material removal rate, Depth of cut $(\mathrm{DoC})$ is the main influence factor are observed.
\end{abstract}

Keywords

GFRP, Composite material, Taguchi design, Surface roughness, ANOVA.

\section{Introduction}

In these days the replacement of traditional engineering materials is fiber reinforced plastics (FRPs) because of their superior advantage over other engineering materials. The advantages encompass high strength to weight ratio, wear resistance, high fracture toughness, electrical conductivity, excellent corrosion and thermal resistance. In various fields the glass fiber reinforced plastic (GFRP) are being broadly used such as aerospace, automobile, chemical industries, offshore power plants, pulp and paper, refinery, oil and gas etc. In addition to that of the application of GFRP composites, expands the prospect of machining such as cutting, turning, milling and drilling etc., and has improved for its fabrication. Since knowledge and experience acquired for conventional materials cannot be applied to such new materials, of which machinability is entirely different from that of conventional materials.

*Author for correspondence

394
In recent years the usage of GFRP composite has been increased which is simultaneously leading to an increased demand for machining. On the other hand users of GFRP composites are facing difficulties while machining it, because of delamination damage, fiber fuzzing, fiber pull out, short tool life, matrix debonding, burning and formation of powder like chips. However, the blemish of composite material lies in their vulnerability to machining damage when subjected to improper machining conditions. In order to minimize the damage in machining, it is important to monitor process Parameters such as cutting speed, feed, depth of cut etc.

Kechagias et al. [1] have done the analysis of surface texture parameters during turning of a reinforced polymer composite. In that analysis observed that the arithmetic mean roughness is mainly depends on the feed rate parameter. Aravindan et al. [2] has described the surface finish of GFRP pipes and investigated technique through Taguchi design 
method. And also determines the percentage of improvement in surface finish and tool wear. Kumar et al. [3] has performed the machinability of unidirectional GFRP composite in turning process. And also evident that the surface roughness increases as feed rate increases. Ntziantzias et al. [4] has found that the cutting force of the glass fiber reinforced polymer composite by Kienzle-victor model. Palanikumar et al. [5] has been established analysis of drilling of GFRP composites using grey relational analysis. Gupta and Kumar [6] have investigated the machinability of unidirectional glass fiber reinforced plastics (UD-GFRP) composite in turning process. In his work, he followed Taguchi L18 orthogonal array is used for experimental design. From that an attempt has been made to model the two response variables, i.e. surface roughness and material removal rate using principal component analysis. Parida et al. [7] has found that the optimum machining condition which leads to minimum surface roughness in the drilling of GFRP composite by means of a response surface methodology. Tank et al. [8] have done the analysis for desirability functional analysis combined with Fuzzy logic to optimize the machining parameters for Turning of GFRP, in order to achieve the best surface characteristics. Karatas and Gökkaya [9] have reviewed the machinability properties and related approaches for GFRP Composites by use of Taguchi optimization techniques. Vasudevan et al. [10] has performed an optimization study on machining of randomly oriented GFRP composite rods in order to determine the best factor level condition.

In the present work, the main objective is to attain the optimal control factor for GFRP while the turning operation is undergone with the process parameters by Taguchi technique and ANOVA. And with the help of MINITAB software to identify the quality characteristics the signal-to-noise $(\mathrm{S} / \mathrm{N})$ ratio was also obtained.

\section{Materials}

Nowadays, most of the fibers used in long lasting plastics are glass fibers shown in Figure 1, as they are economical, easy to accumulate and have high strength and stiffness with respect to the plastics, with which they are used as reinforcement material. The most important properties are low density; resistance to chemicals, lagging capacity is the other beneficial characteristics of the glass fiber. The substrate and the resin are included according to the volume of fraction of the material. The resin tends to be more resistant over time to degradation than polyester resin and is more flexible. The toughness of the composite will increase when the matrix is added. Finally, in the end, while fibers have the good tensile strength they usually have the awful compression strength. The matrix gives compression strength to the composite. Nowadays the polymer composite commonly used matrix is polyester resins. In this work, we have chosen unsaturated isophthalic polyester resin, and it is capable of being cured from a solid state when subject to the right conditions. It has an advantage of high non corrosive resistant content and it has high strength.

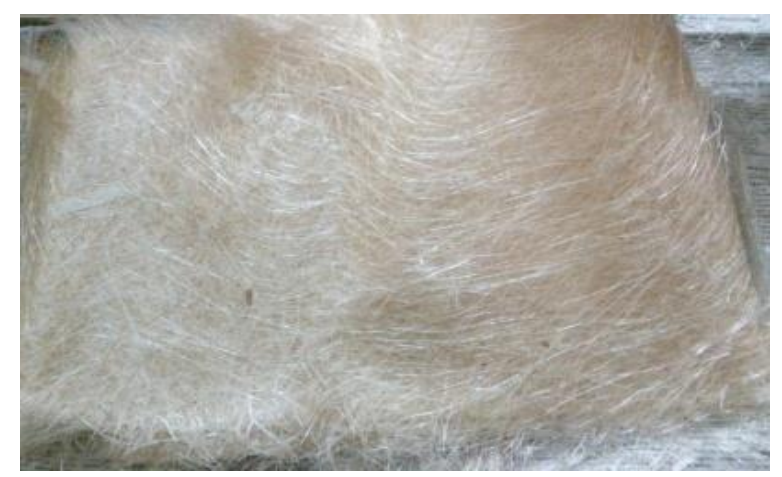

Figure 1 Glass fiber

\section{Experimental details}

The experimental design methods are not very easy to use because they are too complex. In addition, when there is an increase in the number of the process parameters a large number of experiments have to be carried out. In order to solve, the Taguchi method uses a special design of orthogonal arrays to study the entire process parameter with a minimal number of experiments. To measure the quality characteristics deviating from the desired values. In that experimental results are then transformed into a $\mathrm{S} / \mathrm{N}$ ratio with help of Minitab17 software. And the cutting tool used for machining of GFRP composite is cubic boron nitride. It is the hardest tool material and it is used for machining GFRP. During machining shows in Figure 2, it is obviously seen that in lay direction of glass fiber reinforced composites, are cut across and along. While it is difficult to machine the glass fiber reinforced composites because of their properties of the matrix, orientation of fibers, not a uniform character of the material, and also the occurrence of high fiber volume concentration. When machining under a higher depth of cut conditions other than that the ceramic tools are used for roughing and surface finishing operations. The cubic boron nitride (CBN) tools are mainly used for finish turning operation and it is also economical. Machining of glass fiber 
reinforced composite with CBN tool material it is to be at a certain temperature for high speed machining. This will improve the rate of production of the component, while GFRP is undergoing Turning operations with the process parameters by Taguchi's technique and ANOVA. The experimental results were evaluated using Taguchi's technique. The surface roughness tester setup of GFRP is shown in Figure 3.

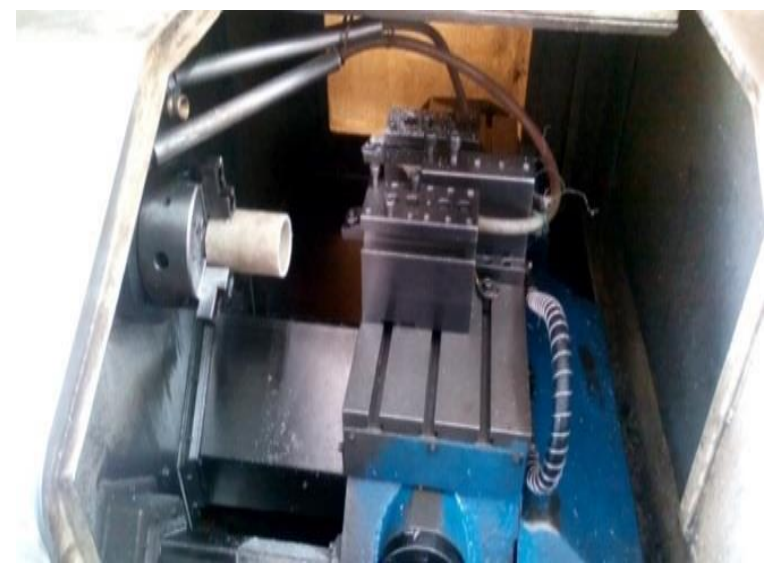

Figure 2 Machining setup of GFRP

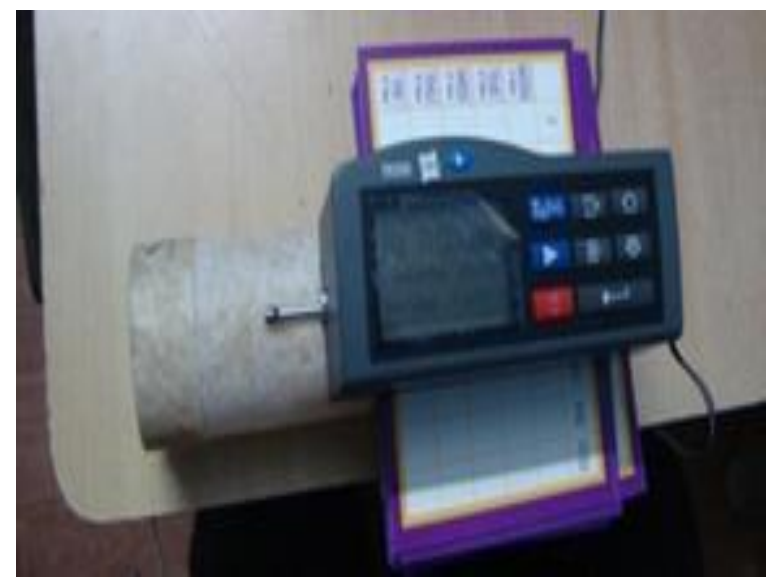

Figure 3 Surface roughness tester setup of GFRP

\section{Results and discussion}

\subsection{Design of orthogonal array}

With the help of MINITAB17 the orthogonal array is formed by means of three process parameters such as Speed, Feed, Depth of cut (DoC); and S/N ratios are calculated. Figure 4 shows the workpieces of GFRP composite. Table 1 presented an orthogonal array L9 formation

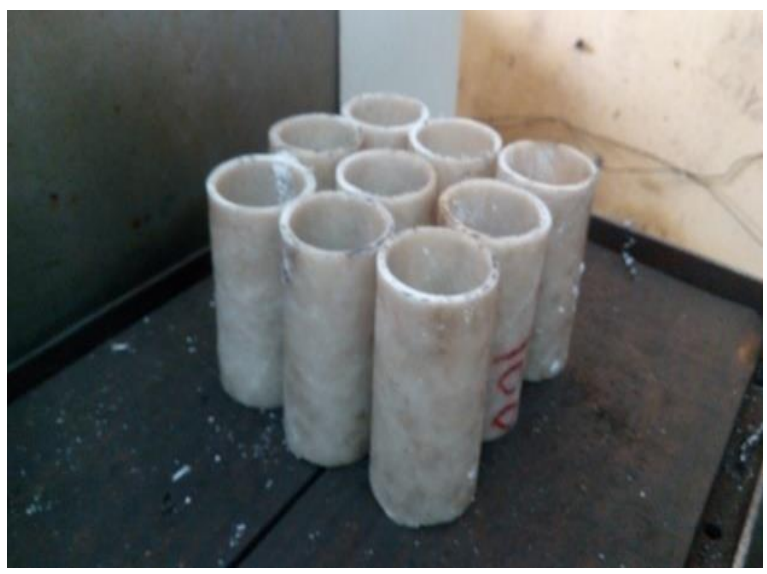

Figure 4 GFRP composite work pieces

Table 1 An orthogonal array L9 formation

\begin{tabular}{lllll}
\hline Trial No. & Designation & Speed & Feed & DoC \\
\hline 1 & A1B1C1 & 1000 & 0.04 & 0.9 \\
2 & A1B2C2 & 1000 & 0.06 & 1.1 \\
3 & A1B3C3 & 1000 & 0.08 & 1.3 \\
4 & A2B1C2 & 1500 & 0.06 & 1.1 \\
5 & A2B2C3 & 1500 & 0.08 & 1.3 \\
6 & A2B3C1 & 1500 & 0.04 & 0.9 \\
7 & A3B1C3 & 2000 & 0.08 & 1.3 \\
8 & A3B2C1 & 2000 & 0.04 & 0.9 \\
9 & A3B3C2 & 2000 & 0.06 & 1.1 \\
\hline
\end{tabular}

\subsection{Experimental analysis}

The graph (Figure 5) represents the material removal rate and the main effect plot for $\mathrm{S} / \mathrm{N}$ ratio. The $\mathrm{S} / \mathrm{N}$ ratio for the material removal rate (MRR) process parameter is presented in Table 2 with the help of Minitab17 software. From this analysis; the result reveals that for material removal rate, depth of cut has been playing a major contribution in machining characteristics of GFRP composite.

The graph (Figure 6) represents the machining time (MT) and the main effect plot for $\mathrm{S} / \mathrm{N}$ ratio. The $\mathrm{S} / \mathrm{N}$ ratio for the machining time process parameter is presented in Table 3 with the help of Minitab17 software. From this analysis; the result depicts that the process parameter such as speed has been playing a major contribution in machining time of GFRP composite. The graph (Figure 7) represents the surface roughness (SR) and the main effect plot for $\mathrm{S} / \mathrm{N}$ ratio. The $\mathrm{S} / \mathrm{N}$ ratio for the $\mathrm{SR}$ process parameter is presented in Table 4 with the help of Minitab17 software. From this analysis; the result illustrates that the process parameter feed rate has been playing a major contribution in surface roughness of GFRP composite. 
International Journal of Advanced Technology and Engineering Exploration, Vol 5(47)

Table 2 Result analysis for MRR and SN ratios

\begin{tabular}{lllllll}
\hline Trial No. & Designation & Speed & Feed & DoC & MRR & SN ratio \\
\hline 1 & A1B1C1 & 1000 & 0.04 & 0.9 & 38.24 & 28.2119 \\
2 & A1B2C2 & 1000 & 0.06 & 1.1 & 19 & 31.3499 \\
3 & A1B3C3 & 1000 & 0.08 & 1.3 & 14 & 23.5218 \\
4 & A2B1C2 & 1500 & 0.06 & 1.1 & 57.5 & 34.8859 \\
5 & A2B2C3 & 1500 & 0.08 & 1.3 & 17.41 & 25.1680 \\
6 & A2B3C1 & 1500 & 0.04 & 0.9 & 20.81 & 26.7731 \\
7 & A3B1C3 & 2000 & 0.08 & 1.3 & 14.45 & 21.9034 \\
8 & A3B2C1 & 2000 & 0.04 & 0.9 & 24.94 & 27.2119 \\
9 & A3B3C2 & 2000 & 0.06 & 1.1 & 39.78 & 31.5452 \\
\hline
\end{tabular}

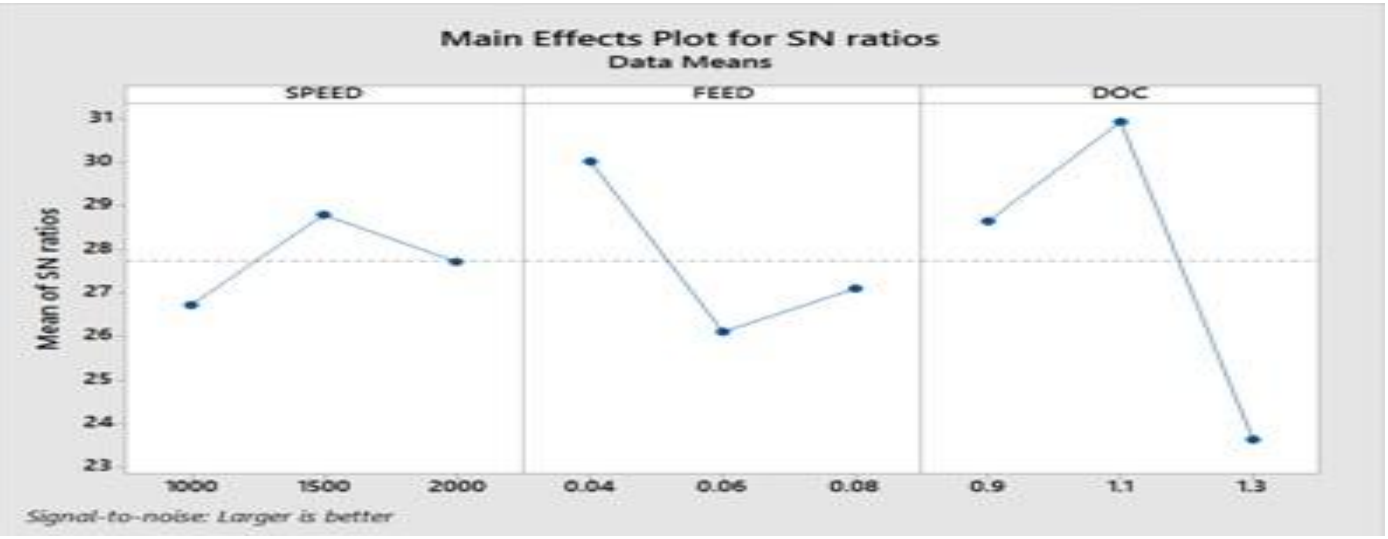

Figure 5 Main effects plot for SN ratios of MRR

Table 3 Result analysis for MT and SN ratios

\begin{tabular}{lllllll}
\hline Trial No. & Designation & Speed & Feed & DoC & MT & SN ratio \\
\hline 1 & A1B1C1 & 1000 & 0.04 & 0.9 & 106 & -42.461 \\
2 & A1B2C2 & 1000 & 0.06 & 1.1 & 60 & -37.560 \\
3 & A1B3C3 & 1000 & 0.08 & 1.3 & 44 & -33.284 \\
4 & A2B1C2 & 1500 & 0.06 & 1.1 & 120 & -35.124 \\
5 & A2B2C3 & 1500 & 0.08 & 1.3 & 43 & -31.327 \\
6 & A2B3C1 & 1500 & 0.04 & 0.9 & 33 & -43.267 \\
7 & A3B1C3 & 2000 & 0.08 & 1.3 & 53 & -28.412 \\
8 & A3B2C1 & 2000 & 0.04 & 0.9 & 34 & -36.125 \\
9 & A3B3C2 & 2000 & 0.06 & 1.1 & 27 & -32.342 \\
\hline
\end{tabular}

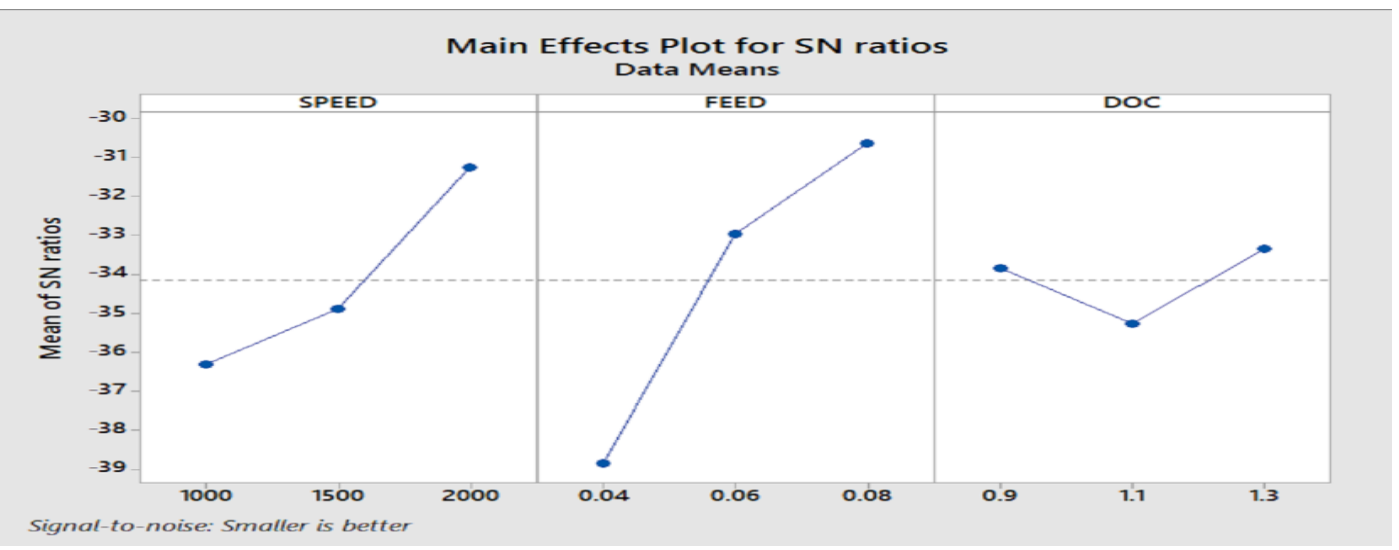

Figure 6 Main effects plot for SN ratios of MT

397 
Jasper et al.

Table 4 Result analysis for SR and SN ratios

\begin{tabular}{lllllll}
\hline Trial No. & Designation & Speed & Feed & DoC & SR & SN ratio \\
\hline 1 & A1B1C1 & 1000 & 0.04 & 0.9 & 0.494 & 7.951 \\
2 & A1B2C2 & 1000 & 0.06 & 1.1 & 0.757 & 2.432 \\
3 & A1B3C3 & 1000 & 0.08 & 1.3 & 0.698 & 3.765 \\
4 & A2B1C2 & 1500 & 0.06 & 1.1 & 0.296 & 9.143 \\
5 & A2B2C3 & 1500 & 0.08 & 1.3 & 0.347 & 8.245 \\
6 & A2B3C1 & 1500 & 0.04 & 0.9 & 0.629 & 3.482 \\
7 & A3B1C3 & 2000 & 0.08 & 1.3 & 0.786 & 2.658 \\
8 & A3B2C1 & 2000 & 0.04 & 0.9 & 0.696 & 3.452 \\
9 & A3B3C2 & 2000 & 0.06 & 1.1 & 0.745 & 2.557 \\
\hline
\end{tabular}

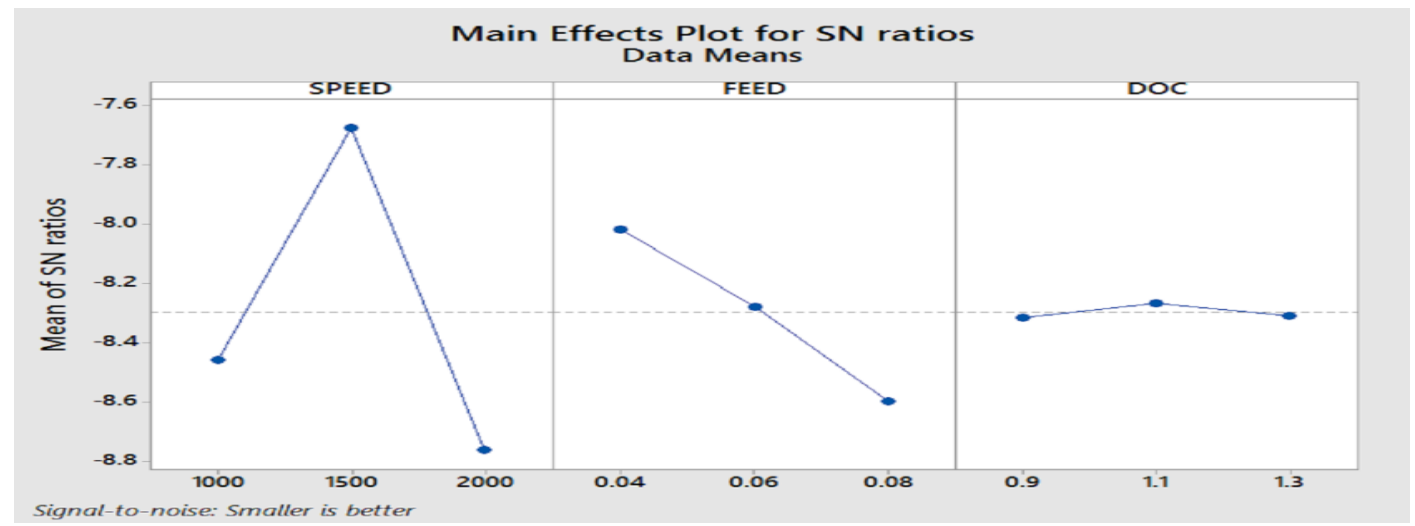

Figure 7 Main effects plot for SN ratios of SR

\section{Conclusions}

Based on this work under dry conditions while GFRP is undergoing turning operations with the process parameters by using Taguchi's technique and ANOVA. The experimental results were evaluated using Taguchi's technique. The conclusions are as follows:

Optimal Control Factor

- For material removal rate is A3 (Speed-2000 rpm) B2 (Feed- $0.04 \mathrm{~mm} / \mathrm{rev}$ ) C1 (DoC-0.9mm).

- For machining time is A2 (Speed-1500 rpm) B1 (Feed- $0.06 \mathrm{~mm} / \mathrm{rev}$ ) C3 (DoC- $1.1 \mathrm{~mm}$ ).

- For surface roughness is A1 (Speed -1000 rpm) B3 (Feed-0.04 mm/rev) C2 (DoC- $0.9 \mathrm{~mm}$ ).

The major contribution of process parameters are

- Surface roughness- Feed.

- Machining time- Speed.

- Material removal rate-DoC.

For the future continuation of this work, optimization of machining parameters of milling operations for GFRP composite and natural fiber reinforced composite materials to be investigated in automobile applications.

\section{Acknowledgment}

The authors thank the Department of Mechanical Engineering, Anna University, Regional Campus Madurai 398 for providing partial support for carrying out this research work.

\section{Conflicts of interest}

The authors have no conflicts of interest to declare.

\section{References}

[1] Kechagias J, Petropoulos G, Iakovakis V, Maropoulos $\mathrm{S}$. An investigation of surface texture parameters during turning of a reinforced polymer composite using design of experiments and analysis. International Journal of Experimental Design and Process Optimisation. 2009; 1(2):164-77.

[2] Aravindan S, Sait AN, Haq AN. A machinability study of GFRP pipes using statistical techniques. The International Journal of Advanced Manufacturing Technology. 2008; 37(11-12):1069-81.

[3] Kumar S, Satsangi PS, Sardana HK. Optimization of surface roughness in turning unidirectional glass fiber reinforced plastics (UD-GFRP) composites using polycrystalline diamond (PCD) cutting tool. Indian Journal of Engineering and Materials Sciences. 2012; 19(3):163-74.

[4] Ntziantzias I, Kechaglas J, Fountas N, Maropoulos S, Vaxevanidis NM. A cutting force model in turning of glass fiber reinforced polymer composite. In international conference on economic engineering and manufacturing systems Brasov 2011 (pp. 24-5).

[5] Palanikumar K, Latha B, Senthilkumar VS, Davim JP. Analysis on drilling of glass fiber-reinforced polymer 
(GFRP) composites using grey relational analysis. Materials and Manufacturing Processes. 2012; 27(3):297-305.

[6] Gupta M, Kumar S. Investigation of surface roughness and MRR for turning of UD-GFRP using PCA and Taguchi method. Engineering Science and Technology, an International Journal. 2015; 18(1):7081.

[7] Parida AK, Routara BC, Bhuyan RK. Surface roughness model and parametric optimization in machining of GFRP composite: Taguchi and response surface methodology approach. Materials Today: Proceedings. 2015; 2(4-5):3065-74.

[8] Tank K, Shetty N, Panchal G, Tukrel A. Optimization of turning parameters for the finest surface roughness characteristics using desirability function analysis coupled with fuzzy methodology and ANOVA. Materials Today: Proceedings. 2018; 5(5):13015-24.

[9] Karataş MA, Gökkaya H. A review on machinability of carbon fiber reinforced polymer (CFRP) and glass fiber reinforced polymer (GFRP) composite materials. Defence Technology. 2018.

[10] Vasudevan H, Rajguru R, Tank K, Shetty N. Optimization of multi-performance characteristics in the turning Of GFRP (E) composites using principle component analysis combined with grey relational analysis. Materials Today: Proceedings. 2018; 5(2):5955-67.

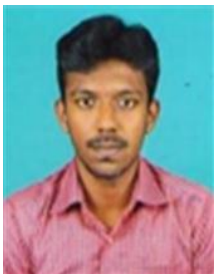

Jasper. $\mathbf{S}$ was born in Madurai district, Tamilnadu, India, in 1995. He received B.E. Degree in Mechanical Engineering from Sri Vidya college of Engineering \& Technology Under Anna University, Chennai, Tamilnadu, India in 2016. He is currently pursuing Master of Engineering in Department of Mechanical Engineering, Anna University, Regional Campus Madurai, Tamilnadu, India since 2018. His current research work includes Composite Materials, Manufacturing Technology, Ceramic Materials, Material Characterization, and Optimization Technology.

Email: joeljasper7@gmail.com

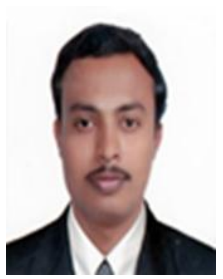

Stalin. B was born in Virudhunagar district, Tamilnadu, India, in 1981. He received B.E. Degree in Mechanical Engineering from the University of Madras, Tamilnadu, India, in 2002, and M.E. Degree in Manufacturing Engineering from the Anna University, Tamilnadu, India, in 2008. He obtained his Ph.D in Mechanical Engineering discipline, in 2015 at Anna University, Chennai, Tamilnadu, India. He has been currently working as an Assistant Professor in the Department of Mechanical Engineering, Anna University, Regional Campus Madurai, Tamilnadu, India since 2010. $\mathrm{He}$ is a Life Member of the Indian Society for Technical Education (ISTE) and The Institution of Engineers (India). His current research interests include Optimization Technology, Manufacturing Engineering, Composite Materials, Material Characterization and Mechanical Properties. 